thex, with the exception of the centre marked 6 , in which - ease peculiar movements of the forearm were, after a while, followed by complete loss of power in that limb, the arm renaining perfectly still even when general convulsions set in. The fact that the mouth was retained wide open during he convulsions may be of importance in sustaining the iew that the source of many of the symptoms was local.

The olfactory bulb was entirely disorganised on the right side, and to a slight extent on the left side also. The disorganisation of the left bulb might have taken place after the test with ammonia was applied, or the right nostril might arve been closed up, or the gas might have caused irritation nerves other than those of special sense.

The fact is at least established that bilateral destruction we antero-frontal region causes neither motor nor sensory paralysis.

Wirksworth, Derby.

\section{THE ARTIFICIAL PRODUCTION OF HUMAN DISEASES IN THE LOWER ANIMALS. ${ }^{+}$}

Br W. LAUDER LINDSAY, M.D., F.R.S.E., PHYSICIAN TO THE MURRAY ROYAL INSTITUTION, PERTH.

DrEECTLY or indirectly, man is the means of producing a sreat amount and variety of disease in other animals. In 3. arance or thoughtlessness, through superstition, prejudice, ratery, for his own selfish ends or to gratify his desire

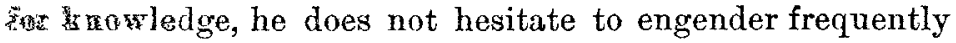
ratu disease in the lower animals, and especially in those when are domestic and subservient immediately to his wiared purposes. He does so, for instance, in the following mromintances:-

E. In the captivity of wild animals in menageries and zoological gardens, whereby they are subjected to a wariety of unnatural and unhealthy influences, such as(a) Deficiency of exercise.

(b) Non-gratification of the sexual or other instincts.

(c) Deficient or improper food and drink.

(d) Deficient temperature and ventilation.

2 In the treatment of home pets, involving an artificial existence similar to that of menagerie captives.

3. In the management of the common domestic animals, such as the horse and cow, including utter inattention to sanitary arrangements in their stables and byres.

1. In the preparation of animals for the market, including-

(a) Over-driving.

(b) Deficiency of food and water.

(c) Exposure to sea-sickness and other exhaustive effects of travel.

5. In the breeding of stock, especially by "in-and-in" breeding.

*. In pursuit of his sports, including--

(a) Racing or chasing to the death.

(b) Inebriation as a practical joke.

7. Intoxication by means of alcohol or narcotics, for the purpose of capture.

* Experiment by the pathologist, in order to a comparison with the diseases of man and to a better knowledge of the nature and mode of treatment of the latter.

"These or other artificially produced diseases should, it apears to me, possess the highest interest, both to the redical profession and to the general public, in connexion with certain social questions that are frequently being disanssed by the public press.

Thus, as regards rabies in the dog, cat, and other animals, 2 can be-and cannot too often and distinctly be-shown that man, in his stupidity, corporate orindividual, not unfrequently produces the very disease he is so desirous of preventing or of stamping out. It is one of the many popular errors ${ }^{2}$

I Other remarks upon and illustrations of the same subject may be Tound in the following papers:-(1) "The Transmission of Disease between Man and the Lower Animals," Edinburgh Veterinary Review, . S ly, 1858; (2) "Community of Disease in Man and other Animals," Brit. and For. Med. -Chir. Review, Jan., 1874; (3) "Madness in Animals," Sournal of Miental Science, July, 1871.

2 I lewret to find that these mischievous errors, or many of them, are supported and propagated by the high authority of the veteran Sir Thomas Watson, in his paper on "Hydrophobia and Rabies," in the December number (1877) of the Ninsteenth Century. connected with canine rabies - the belief that it always arises from the bite of a rabietic animal, the fact being that it is also generated de novo by a series of conditions which man has completely under control, which he himself indeed creates.

The question of general insanity in the lower animalsand especially of acute mania-is an equally important one; for popularly, as well as by both the medical and veterinary professions, all "mad" dogs or other animals are supposed to be simply rabietic, whereas rabies is only one form of animal insanity, and a comparatively rare form. ${ }^{3}$

Artificial tuberculosis, especially in the cow, has the most important bearing on the generation of scrofula in its varion forms in the human subject, more particularly in infant and children, from the use of diseased milk and meat.

Again, the vivisection agitation opens up the question of the utility of the operations of experimental pathologists, especially in contrast with the other classes of artificial disease that have been alluded to-for instance, those which result from the gratification of man's love of "sport" so. called. A quarter of a century ago I was myself engaged in researches in experimental pathology, having for their object a better knowledge, in man as in other animals, of the whole natural history of (1) cholera ; ${ }^{4}$ (2) diarrhoea, dysentery, and other disorders allied to cholera $;^{5}$ and (3) the antagonism of poisons and medicines. From that time onwards I hav given much attention to the progress of research in several departments of experimental pathology; and it so happen that I have had special occasion during the last five years to study the preventable diseases produced by man in other animals, mainly by his inadvertence or stupidity, but also by his passion for sport. The result of a comparison of the different kinds of artificial disease produced by man in other animals leaves me in no doubt that those created by the experimental pathologist constitute but a tithe of those that are the fruit even of man's sports, field or otherwise.

As regards the artificial production of rabies-its generation de novo - the following opinions are deserving of note in relation to the current hydrophobia panic in London, Glasgow, and other of our great cities. A certain cross-bred spaniel five months and a half old "had not left its mother. It never went out, and it was naturally very quiet." When the mother became in rut, " the young dog, excited by the odour, made unsuccessful attempts to approach her. It ardour was extreme, its agitation incessant, and its appetito became almost null." Three days afterwards, being asleep, "it wakened up from its torpor and flew at the man" who fed it. When taken to the infirmary of an eminent reterinary surgeon in Paris, its rabies was recognised "by tho characteristic howling only. During the three succeeding days it refused all kinds of food." On the fourth it wal paralysed, and on the fifth it died.

A similar case of what Fleming calls "spontaneous" rabies occurred from "undue excitement of the venereal organism. ...... In the adjoining box was a bitch in rut and the effluvia from her caused the most ardent venerie excitation. For nearly fifteen days this unfortunate creature - condemned to such tantalising proximity-manifested the utmost agitation." Then it became "furiously rabid, and its owner affirmed it had never been bitten"- seeing that it was "so valuable that it was not allowed to stray, but wos kept in a loose box in a stable." 8

Results of the same kind have been produced inten. tionally - that is, experimentally - by confining severa dogs beside a bitch in rut. "The same exciting competition commenced as in ordinary cases, accompanied by the same maddening jealousy and fierce combats...... The results obtained in this way by Toppolin were so constant and decisive that he was perfectly convinced a to the effect of jealousy and rage, conjoined with \& powerful sexual desire, in producing a rabid condition." Nevertheless, Fleming very cautiously sums up : "There may be some foundation for the supposition that intense sexual excitement may produce rabies, though at present there are only probabilities in favour of it. ..... The bite of an irritated dog, or of one in rut, might become momentarily virulent and cause rabies"; 10 and he cites an illustrative case. "Jealousy, excitement, irritation, and anger .........

3 Vide what I have said on this subject in my paper on "Madness in Animals" (already quoted).

4 Edin. Med. and Surgical Journal, 1854; Gazette Hebdom. de Mád.

et de Chirurgie, 1854 ; and Association Medical Journal, 1854.

5 Association Medical Journal, 1855.6 Ibid., 1854.

7 Fleming: "Rabies," pp. 109-10. 8 Ibid., p. 110

9 Ibid., pp. 108-8. 10 Ibid., pp. 110 and 119. 
consequent on sereral (males) competing for the same female, are sufficient, and even do occasion the appearance of rabies in them. ........ The incessant competition, the extreme excitement, aud the savage fights among amorous dogs in pursuit of a female in rut have been decided upon as sufficient to piedlispose them to madness." 11

But predisposition is not the disease itself, though it is of quite as great importance, because if it were more attended to there would necessarily be much less rabies. As illustrations of predisposition to, or of the predisposing causes of rabies, all keepers of dog pets should be made aware of the fact that "Dogs kept only for luxury are the most dangerous......The dogs de licxe kept in apartments, petted, and abundantly fed, and whose venereal appetites are incompletely or never gratified," are the most liable to rabies; and, again, dogs " belonging to irritable or nervous breeds, or else dogs which, having been kept all their lives chained up, have become very vicious......insufficiently exercised, and seldom allowed to gratify their sexual propensities," are specially predisposed. 12 "It is noteworthy," says a New York newspaper in 1874, "that in every instance in which persons bitten by mad dogs during the last six months in this city have died of hydrophobia, the dog inflicting the wound has been a household pet. The street ${ }^{13}$ dogs have inoculated no one with hydrophobia, so far as is known. It is the house dogs of the male sex, who are overfed and forced to lead an unnatural life, who become mad and communicate hydrophobia."14 In reference to similar occurrences in our own country, Youatt exclaims, "We pity, or almost detest, the folly of those by whom their favourites are indulged and spoiled, even more than their own children." The latter clause, however, is surely unnecessary, inasmuch as pet dogs are almost invariably kept by women who have no children on whom to lavish their overflowing "maternal instinct." Further " excitement, anger, sexual irritability, terror, ...... assist in the production of rabies." 16 The effect of mere confinement to a house was well exhibited in the case of a certain tamed wild cat, which never slept in a certain house. "We compelled her to do so once," says Miss Clara Rossiter, in her "Anecdotes of Pets," "and the poor creature was so ill we did not attempt to do it again." Confinement, in association with solitude, silence, and darkness, is an apt cause of certain forms of insanity, especially melancholia with panphobia. We are told moreover that "confinement is almost certain in many dogs to produce skin disease; and it predisposes young dogs to convulsive and rheumatic attacks." 17

It would appear also that physical pain, however produced, is occasionally both a direct and predisposing cause of rabies. "Extreme pain or intense suffering," is credited with the production of rabies in such a case as the following:-A castrated animal, on its return home, " retired to a corner of the house, refusing all kinds of food." It became gradually "irritable and morose, threatening to bite the farm people it had previously been fond of." Then it attempted to "bite some cattle, and could not be driven back by its master's voice nor by threatenings with a stick." Subsequently it bit a horse and five cattle, all of which died of rabies. Fleming suggests that if mere pain could produce rabies, how comes it that the disease is so rare, while its alleged cause is so frequent ${ }^{18}$ This brings up as before the question of predisposition, of immediate as contrasted with remote causes, a question too wide, how ever, to be here or at present entered upon.

The really important practical matter is that certain inflnences or causes, be they remote or immediate, predisposing or exciting, conduce to the production of rabies in the dog and other animals; that the operation of these influences can easily be prevented by man, and that it should be prevented. In other words, just as rabies is, frequently at least, produced by man, it is equally, in certain cases, preventable by him. There is a grave responsibility, then, if its generation de novo or its propagation is not prevented.

"Above all things," says Fleming, "19 "dogs should not be

11 Fleming: Rabies, p. 116.

12 Ibid., p. 107

13 This is borne out by the experience of Constantinople, and other Eastern cities, in which street dogs abound, but in which nevertheless rabjes and hydrophobia are unknown.

14 As inuted in the North British Daily Mail (of Glasgow), July 31st,

15 Work on The Dog, p. 146.

is Fiening: Rabies, p. Its.

p. 36

Rabies, pp. 113-14

British Medical Journal, July 11th, 1874, needlessly excited or abused. ..... If it should happen that an excited dog bites anyone, the person who excited it should be held guilty of a legal offence," and, in point of fact, he is so by the Austrian and French, and should be equally so by the English law; for there would appear to be cases of latent rabies, where the disease is stimulated into full development, or where its dangerous symptoms are developed, only on or by man's interference. 'Thus we are told that fury, even in the rabietic $\log$, is usually due to provocation or excitement of a preventable kind. ${ }^{20}$ Professor Saint-Cyr, of Lyons, mentions a dog whose rabidity was not suspected till "on its owner scolding it, it flew at and bit him." It subsequently proved that it " had employed itself pulling shavings about a joiner's shop for two days, and no attention had been paid to this singular but significant occupation,":1 an occupation generally supposed by veterinarians to be illustrative of that morbid appetite which is one of the few diagnostic signs of rabies. A rabietic pig "could scarcely be made to move, even by beating; but if any white body was placed before it, such as a piece of paper tied to a long stick, it immediately sprang up in a furious state...... appearing to be very much agitated. Every time the experiment was made, the same effect was produced."

Rabies has repeatedly been produced intentionally for experimental purposes by man; but it does not follow that the experimenters in such cases were physicians. More generally they have been veterinarians-authorities presumably competent to deal with such experiments both in their method and aim. In a guinea-pig artificially inoculated with man's saliva, the animal's "violence induced convulsions of his whole frame, and they might be produced at pleasure by dashing a little water at him." Maupertius produced hydrophobia in the $\log$ by subjecting it to the bite of an irritated scorpion, says Pierquin ; but he pertinently puts the question whether an ordinary bite of the non-irritated animal would not have produced a similar result, and whether the result was really hydrophobia. He makes the suggestion. in connexion with the fact that animal bites are fatal sometimes by tetanus or other diseases, and that irritation or passion may add to the malignity of a bite. "The dying bite of a beast of prey is always the worst," says Sir A. Alexander. ${ }^{24}$

(To be continued.)

\section{OVARIOTOMY PERFORMED ON THE ANTI SEPTIC METHOD, THE PATIENT BEING:} IN A STATE OF PYREXIA; RECOVERY.

\section{By JOHN WILLIAMS, M.D.,}

ASSISTANT OBSTETRIC PHYSICIAN TO UNIVERSTTY COLLEGE HOSPITAT

THE notes of the following case were taken by Mr. R. S. Miller, late obstetric physician's assistant.

Mrs. D-, who had had two children, was seen by Mr. Keele, of Highbury, in August, 1876. She complained of a severe pain in the left inguinal region; it had come ou suddenly, and was greatly relieved by sedatives and hot applications. On examination the uterus was found somewhat enlarged, and a diagnosis of pregnancy was made. The abdomen grew rapidly until March, 1877, when Dr. Glover saw her in consultation with Mr. Keele. Pregnancy complicated by an ovarian tumour was diagnosed, and labour induced. A male child of six months was soon born, and the patient recovered well from the effects of the labour. Before delivery the abdomen measured fifty-two inches in circumference, after delivery forty-seven inches. The tumour grew rapidly, and on April 3rd she was tapped, when thirty pints of thick grumous fluid were drawn off. She rapidly improved, and at the end of May was able to walk out. The cyst, however, began to fill again, sickness set in and became very distressing, the temperature rose, and on Aug. 16th she was again tapped, when fifteen pints of thick grumous fluid were drawn off. Though relieved from the effects of pressure, she did not improve, for the sickness increased, the temperature continued high and once rose to $104^{\circ}$, she had much.

20 Fleming, Rabies, p. 229 21 Ibid., foot-note, p. 237.

23 Youatt on the Dog, p. 149

22 Ibid., foot-note, p. 281

24 As quoted in Anderson's Lion and Elephant, p. 148. 